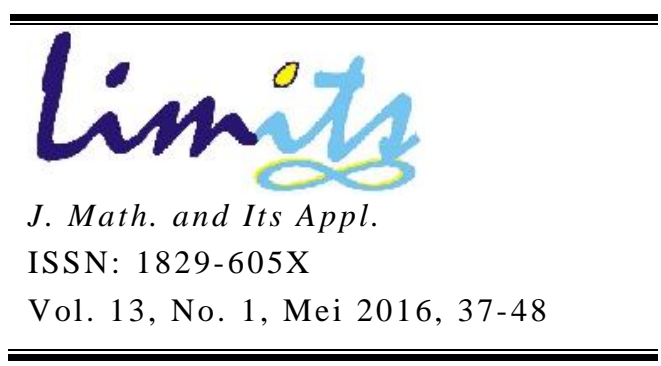

\title{
DESAIN SISTEM KENDALI TEMPERATUR UAP SUPERHEATER DENGAN METODE FUZZY SLIDING MODE CONTROL
}

\author{
Mardlijah $^{1}$, Mardiana Septiani ${ }^{2}$,Titik Mudjiati ${ }^{3}$ \\ 1,2,3 Jurusan Matematika, Fakultas MIPA, Institut Teknologi Sepuluh Nopember (ITS) \\ 르리lijah@matematika.its.ac.id, ${ }^{2}$ mardiana.septiani@gmail.com \\ 3mudjiati@matematika.its.ac.id
}

\begin{abstract}
Abstrak
Pada suatu sistem PLTU, boiler adalah komponen yang memegang peranan penting. Superheater merupakan salah satu komponen dalam boiler yang berfungsi untuk merubah uap jenuh menjadi uap panas lanjut. Variabel yang diukur dalam superheater adalah temperatur uap dimana set point yang harus dicapai adalah $814 \mathrm{~K}$. Pada penelitian ini dirancang sistem pengendali FSMC pada sistem temperatur uap superheater dan analisis terhadap performansi sistemnya dengan membandingkan metode FSMC dengan SMC. Pengendali FSMC dapat menghasilkan temperatur uap yang stabil di sekitar $813.9 \mathrm{~K}$ baik tanpa gangguan maupun dengan gangguan eksternal dan internal, sedangkan dengan pengendali SMC, temperatur uap dapat stabil di sekitar $813.5 \mathrm{~K}$. Sehingga didapatkan kesimpulan bahwa pengendali FSMC dapat menghasilkan temperatur uap yang lebih akurat (error yang lebih kecil) daripada SMC, namun pengendali FSMC memiliki kekurangan yaitu membutuhkan waktu yang lebih lama daripada pengendali SMC.
\end{abstract}

Katakunci: Superheater; Sliding Mode Control; Fuzzy Sliding Mode Control

\section{Pendahuluan}

Pembangkit Listrik Tenaga Uap (PLTU) merupakan salah satu produsen listrik yang diandalkan untuk dapat memenuhi kebutuhan energi listrik di Indonesia. PLTU memanfaatkan energi kalor untuk diubah menjadi energi listrik. Mula-mula energi kalor dipakai untuk menguapkan air di dalam boiler hingga mencapai tekanan dan temperatur tertentu. Uap tersebut digunakan untuk menggerakkan turbin, sehingga turbin dapat menggerakkan generator listrik

Pada suatu sistem PLTU, boiler adalah komponen yang memegang peranan penting. Superheater merupakan salah satu komponen dalam boiler 
yang berfungsi untuk merubah uap jenuh menjadi uap panas lanjut. Variabel yang diukur dalam superheater adalah temperatur uap dimana set point yang harus dicapai adalah $541^{\circ} \mathrm{C}$. Pengendalian temperatur uap pada superheater adalah hal yang sangat penting untuk keamanan dan efisiensi operasional dari boiler. Disinilah uap yang digunakan untuk memutar turbin pertama kali dihasilkan.

Salah satu metode yang cukup diminati dan menjadi usulan para ilmuwan dewasa ini adalah Sliding Mode Control (SMC). Pengendali SMC memiliki beberapa kelebihan, yaitu sifatnya yang sangat robust, yang mampu bekerja dengan baik pada sistem nonlinear yang memiliki ketidakpastian model ataupun parameter. Namun demikian, pengendali SMC masih memiliki kekurangan, yaitu sedikit lebih rumit dalam perancangannya dan masih adanya error [1].

Untuk memperbaiki performansi sistem, SMC murni dimodifikasi dan dikombinasikan dengan konsep Fuzzy Logic Control (FLC) sehingga hasil modifikasi ini disebut Fuzzy Sliding Mode Control (FSMC). Sehingga pada penelitian ini, akan dirancang suatu desain sistem kendali temperatur uap pada superheater dengan menggunakan metode Fuzzy Sliding Mode Control.

\section{Uraian Penelitian}

\subsection{Sistem Superheater}

Superheater merupakan suatu komponen dalam boiler yang digunakan untuk memanaskan lanjut uap saturasi sampai dihasilkan uap yang benarbenar kering. Pada pengendalian temperatur superheater ini, temperatur harus dijaga supaya selalu mencapai set point, agar sesuai dengan temperatur yang digunakan untuk memutar turbin. Bila temperatur melebihi set point, maka akan menjadi uap kering yang membahayakan bagi turbin serta bahan bakar akan terbuang sia-sia. Oleh karena itu, jika temperatur melebihi set point, desuperheater (superheater spray) akan mengeluarkan air yang berfungsi unuk menurunkan suhu hot steam hingga mencapai set point. Sistem temperatur uap superheater ditunjukkan pada Gambar 1.

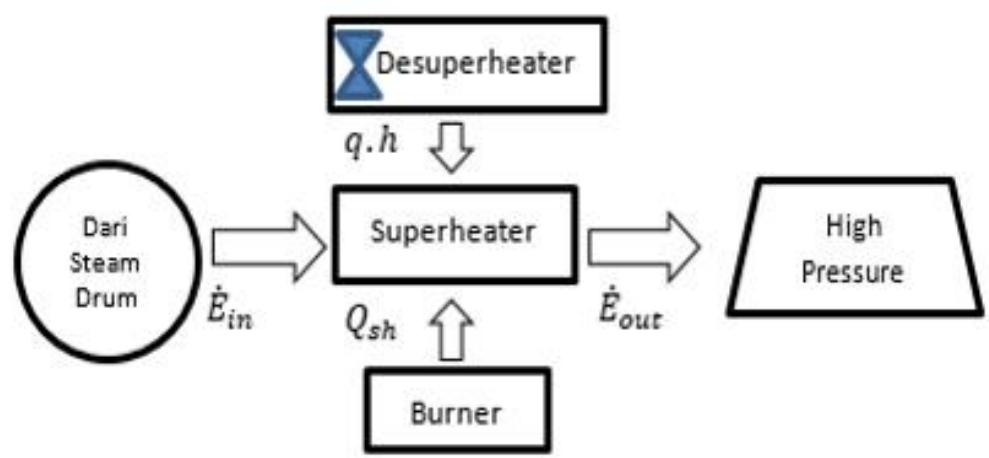

Gambar 1 Sistem Temperatur Uap pada Superheater 
Hukum kesetimbangan energi menyatakan bahwa laju energi yang masuk ke dalam sistem adalah sebanding dengan laju energi yang keluar dari sistem dan energi yang terakumulasi di dalam sistem itu sendiri [2].

Persamaan yang dibentuk dari hukum kesetimbangan energi pada superheater secara matematis adalah:

$\dot{E}_{\text {sh }}=\dot{E}_{i 1}-\dot{E}_{o}+Q$

Sehingga dapat ditulis:

$\frac{d}{d}=\frac{1}{V_{s h} \cdot \hat{\mu}}\left(\dot{m}_{i 1} \cdot\left(T_{\mathrm{i} 1}-T_{r}\right)-\dot{m}_{o} \cdot\left(T_{o}-T_{r}\right)+\frac{Q_{s h}}{c_{p}}+\frac{4 \cdot h}{c_{p}}\right)$

Dengan $\dot{E}_{s h}$ Total laju energi pada superheater, $\dot{E}_{\bar{l}}$ Laju energi input superheater, $\dot{E}_{0}$ Laju energi output superheater, $\rho$ Massa jenis steam superheater, $V_{s h}$ Volume superheater, $c_{p}$ Kalor spesifik superheater, $\dot{m}_{i 1}$ Laju aliran input massa steam superheater, $\dot{m}_{0} \quad$ Laju aliran output massa steam superheater, $T_{i 1}$ Temperatur input superheater, $T_{0}$ Temperatur output superheater, $Q_{s h}$ Kalor pembakaran pada superheater per detik, $q$ Laju aliran massa steam desuperheater dan $h$ Entalpi steam desuperheater

\subsection{Sistem Pengendalian}

Secara umum, sistem pengendali dapat digambarkan sebagai berikut. [3]

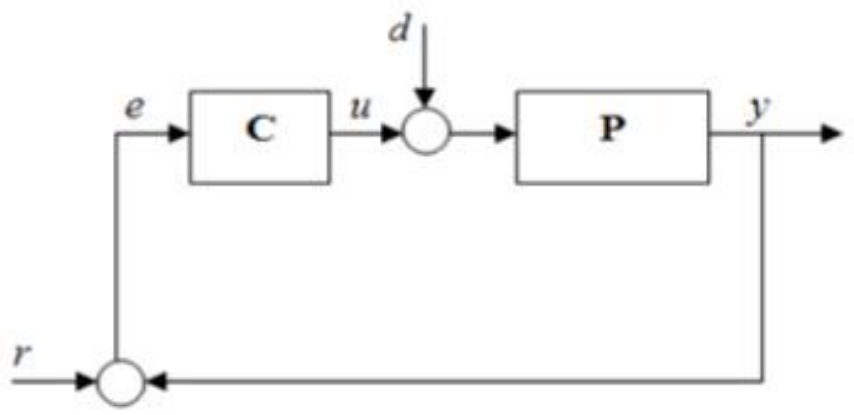

Gambar 2 Diagram blok sederhana dari sistem lup tertutup.

Gambar 2 menunjukkan diagram blok sederhana dari sistem lup tertutup dengan $r$ adalah reference point atau nilai yang diinginkan, $d$ gangguan bagi sistem, e sinyal error, u control input, $y$ keluaran sistem, $\mathrm{C}$ sistem pengendali, dan $\mathrm{P}$ adalah plant.

\subsection{Sliding Mode Control (SMC)}

Sliding Mode adalah merupakan teknik umpan balik terlebih dahulu dengan mendefinisikan permukaan. Sistem yang dikendalikan (variabel) akan dipindahkan ke permukaan dan sistem gerak diarahkan ke titik ekuilibrium yang diinginkan. [4].

Pandang suatu sistem dinamis [5]:

$$
x^{(n)}(t)=f(x, t)+b(x, t) \cdot u+d(t)
$$

dimana $u$ adalah control input, $x$ merupakan vektor keadaan, $f(x, t)$ dan $b(x, t)$ berupa fungsi terbatas, $d(t)$ gangguan eksternal. Jika $x_{d}$ merupakan $x$ yang diinginkan, maka tracking error-nya dapat dinyatakan dengan: 


$$
e(t)=x(t)-x_{d}(t)
$$

Fungsi switching yaitu permukaan $S(x, t)$ di dalam ruang keadaan $R^{n}$, memenuhi persamaan:

$$
S(x, t)=\left(\frac{d}{d}+\lambda\right)^{n-1} e
$$

Dengan $\lambda$ berupa konstanta positif. Dimana fungsi switching ini digunakan untuk menentukan besarnya nilai $u$ agar memenuhi kondisi sliding.

Permukaan sliding (sliding surface) merupakan persamaan yang memenuhi $S(x, t)=0$.

Besar nilai control input pada SMC bergantung pada nilai S, sehingga memenuhi pertidaksamaan yang disebut kondisi sliding. Kondisi tersebut ditulis dalam bentuk sebagai berikut :

$$
S \dot{S}<0 \text { atau } \dot{S} S \quad(S) \leq-\eta
$$

\subsection{Fuzzy Sliding Mode Control (FSMC)}

Untuk memperbaiki performansi sistem SMC, dilakukan modifikasi pada SMC dengan menggunakan FLC. Modifikasi ini umumnya disebut sebagai Fuzzy Sliding Mode Control (FSMC) atau Sliding Mode Fuzzy Logic Control (SMFLC).

Suatu pengendali FSMC tersusun oleh dua macam pengendali, yaitu pengendali SMC dan FLC. Pengendali SMC tidak bekerja secara penuh sebagaimana pengendali SMC murni. Namun, setelah melalui beberapa tahapan yang akan diproses dengan pengendali FLC. Inputan pada pengendali fuzzy adalah dua variabel yang ditentukan sebelumnya melalui pengendali SMC, yaitu $s$ dan $d$. Variabel - variabel ini selanjutnya diproses dengan pengendali FLC sehingga keluaran dari pengendali FLC ini adalah control input $u$ untuk plant [7].

Perancangan pengendali FSMC bekerja sebagaimana SMC, yaitu menggunakan sebuah permukaan sliding. Oleh karena itu, tetap digunakan fungsi switching untuk menentukan besarnya nilai $u$. Namun langkah langkah dalam merancang pengendali FSMC lebih sederhana daripada merancang pengendali SMC, terutama dalam hal menentukan besarnya control input $u$. Karena pada FSMC, besarnya $u$ diperoleh dari aturan fuzzy dengan bentuk:

$$
R_{C}^{i}: \text { Jika } s=L_{S_{i}} \text { dan } d=L D_{i} \text { maka } u=L U_{i}
$$

dimana $s$ adalah jarak antara vektor keadaan dan permukaan sliding, dan $d$ adalah jarak antara vektor keadaan dan vektor normal ke permukaan sliding dimana vektor normal melalui titik asal dari ruang keadaan. $L S_{i} \epsilon^{\prime}$ dan $L D_{i} \epsilon^{\prime} \quad$ masing - masing adalah nilai fuzzy dari variabel keadaan fuzzy $s$ dan $d$ pada daerah fuzzy ke-i dari ruang keadaan fuzzy. $\boldsymbol{L} \boldsymbol{U}_{\boldsymbol{i}}$ adalah vektor masukan fuzzy yang berkorespondensi pada daerah fuzzy ke- $i$ dari ruang keadaan fuzzy. TS, TD dan TU adalah himpunan dari $s, d$ dan $u$ yang mencakup range dari nilai fuzzy $s, d$ dan $u$. 


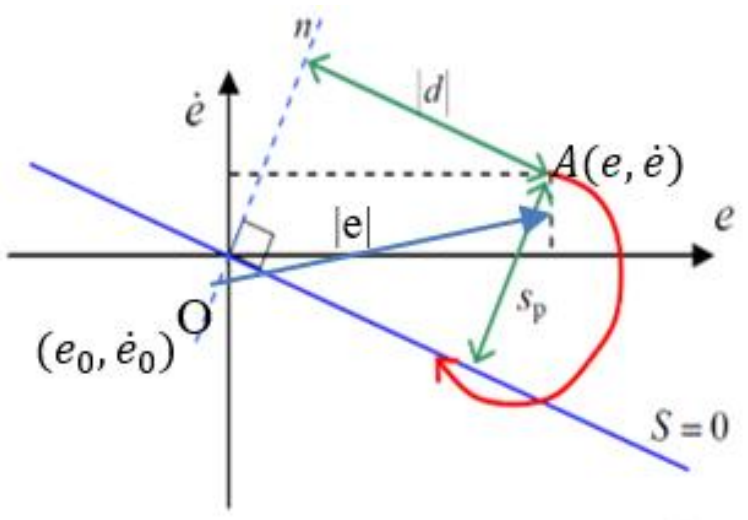

Gambar 3 Interpretasi Grafis $s_{p}$ dan $d$

Berdasarkan interpretasi grafis $s_{p}$ dan $d$ pada bidang $e \dot{e}$, nilai $s_{p}$ dapat diperoleh dengan menggunakan rumus jarak titik A $(e, \dot{e})$ ke garis $S=0$, dengan $S=\dot{e}+\lambda=0$ sebagai berikut:

$$
S_{p}=\frac{|\dot{e}+\lambda|}{\sqrt{1^{2}+\lambda^{2}}}
$$

Sedangkan untuk mendapatkan nilai $d$ dapat digunakan teorema pytagoras, sehingga diperoleh :

$$
d=\sqrt{e^{2}-s_{p}^{2}}
$$

Aturan umum Fuzzy untuk Pengendali FSMC ditunjukkan pada Tabel 1 berikut.

Tabel 1 Aturan Umum Fuzzy untuk Pengendali FSMC

\begin{tabular}{|c|c|c|c|c|c|c|c|c|}
\multicolumn{1}{l|}{} & \multicolumn{9}{|c|}{} \\
\hline & NB & NM & NS & NZ & PZ & PS & PM & PB \\
\hline \multirow{4}{*}{$d$} & PB & PB & PB & PB & NB & NB & NB & NB \\
\hline M & PB & PB & PB & PM & NM & NB & NB & NB \\
\hline S & PB & PB & PM & PS & NS & NM & NB & NB \\
\hline Z & PB & PM & PS & PZ & NZ & NS & NM & NB \\
\hline
\end{tabular}

\subsection{Perancangan Pengendali}

FSMC merupakan kombinasi dari SMC dan FLC (Fuzzy Logic Control). Sehingga untuk merancang pengendali FSMC diperlukan suatu fungsi switching $S$ sebagai berikut:

$$
S=\dot{\tilde{T}}+\lambda \tilde{T}
$$

Dengan

$$
\begin{aligned}
& \tilde{T}=T-T_{d} \\
& \dot{\tilde{T}}=\dot{T}-\dot{T}_{d}
\end{aligned}
$$

Permukaan slidingnya adalah :

$$
\dot{\tilde{T}}+\lambda \tilde{T}=0
$$

Penentuan nilai control input u pada FSMC menggunakan dua variabel masukan pada fuzzy yaitu $s_{p}$ dan $d$ seperti yang telah dibahas sebelumnya. Sehingga didapat : 


$$
\begin{aligned}
S_{p} & =\frac{|\dot{\vec{T}}+\lambda \tilde{T}|}{\sqrt{1^{2}+\lambda^{2}}} \\
d & =\sqrt{\tilde{T}^{2}-s_{p}^{2}}
\end{aligned}
$$

Pada penentuan fungsi keanggotaan, perlu diketahui batasan nilai $s_{p}$ dan $d$. Hal ini dapat dilihat dari hasil scope nilai $s_{p}$ dan $d$ dari perancangan pengendali SMC yang telah dibuat sebelumnya. Sehingga didapat intervalnya yaitu:

$$
S_{p} \in[0730]
$$

$d \in\left[\begin{array}{ll}0 & 530\end{array}\right]$

Setelah diketahui masing-masing variabel, selanjutnya dirancang fungsi keanggotaan dari $s_{p}$ dan $d$ seperti ditunjukkan pada Gambar 4 dan Gambar 5.

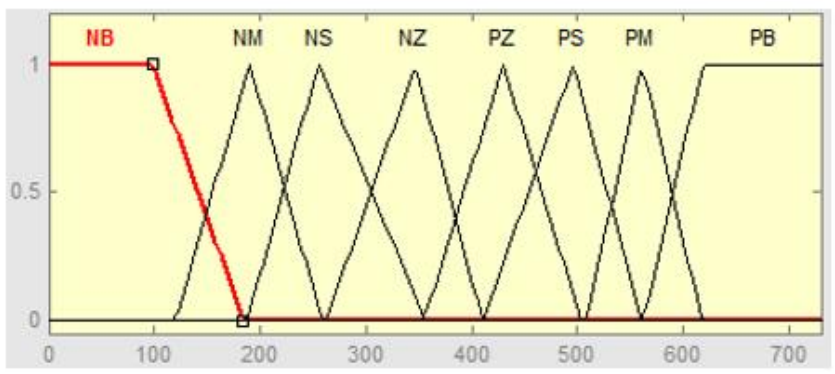

Gambar 4 Fungsi Keanggotaan $s_{p}$ pada Pengendali FSMC

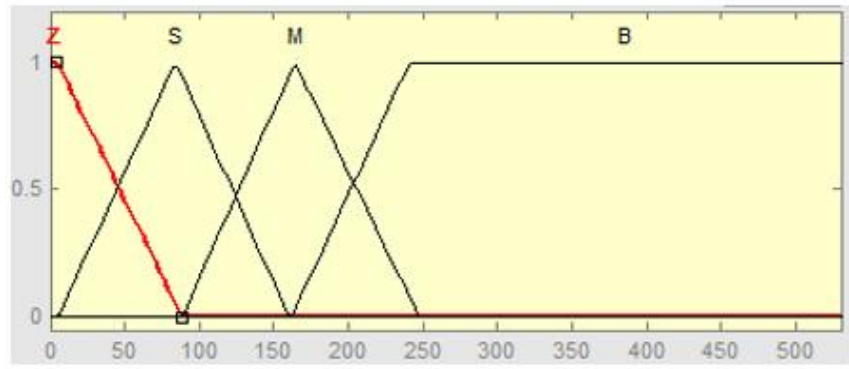

Gambar 5 Fungsi Keanggotaan $d$ pada Pengendali FSMC

Nilai control input $u$ secara umum ditentukan dengan menyesuaikan kemampuan dari $q$ atau kalor pembakaran yang dikeluarkan. Pada penelitian ini fungsi keanggotaan nilau $u$ dirancang sedemikian sehingga diperoleh seperti pada Gambar 6.

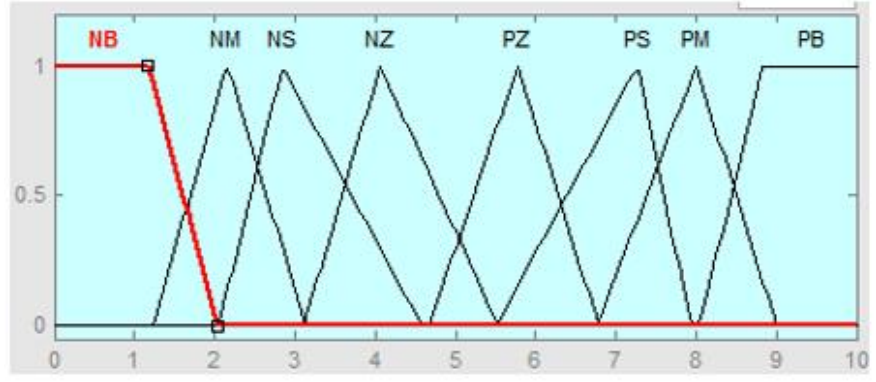

Gambar 6 Fungsi Keanggotaan Control Input $u$ pada Pengendali FSMC 
Aturan fuzzy yang digunakan untuk pengendali FSMC pada sistem superheater dapat dilihat pada Tabel 1.

Setelah diperoleh rancangan fungsi keanggotaan dan aturan fuzzy, langkah selanjutnya adalah mengimplementasikan diagram blok dan rancangan fuzzy pada Matlab. Hasil perancangan FSMC pada Simulink dapat dilihat pada Gambar 7, dimana rangkaian sistem berupa lup tertutup dengan sistem pengendali berupa pengendali fuzzy.

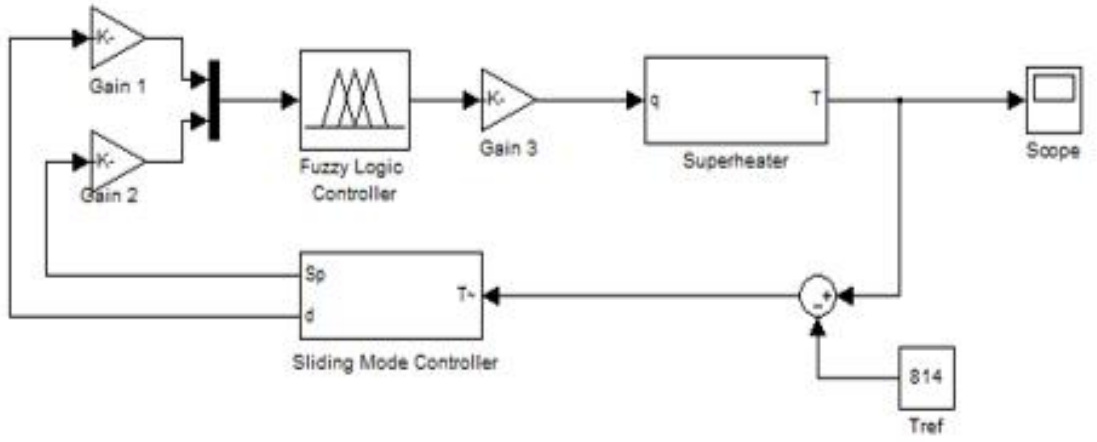

Gambar 7 Diagram Blok Sistem Superheater dengan Pengendali FSMC

Pada Gambar 7, Blok Subsistem Superheater didapat dari persamaan (1), dan blok Subsistem Sliding Mode Control didapat dari persamaan (2) dan (3). Agar dapat dibandingkan dengan hasil pengendalian SMC, pada pengendali FSMC ini digunakan nilai $\lambda=0,3$. Sedangkan nilai gain1, gain2, dan gain diperoleh dengan cara trial and error. Pada penelitian ini diambil nilai-nilai gain untuk sistem pengendali FSMC yaitu g1 $=0.0076$, g2 $=0.0001$, dan g3 $=0.7$.

\section{Analisis Hasil Simulasi}

Pada simulasi akan digunakan rancangan SMC sebagai pembanding dengan rancangan FSMC. Selanjutnya dari masing-masing pengendali akan dilakukan pengamatan tanpa gangguan dan dengan gangguan. Gangguan yang diberikan berupa sinyal impuls dan square. Hal ini dilakukan untuk menguji sifat robust sistem pengendali terhadap ketidakpastian sistem dengan menganalisa performansi sistem. Setiap simulasi yang yang dilakukan menggunakan nilai $C p=2822, \rho=50.4, V_{s h}=21.45$, dan $h=83562$. Sedangkan parameter-parameter yang digunakan $\dot{m}_{i\urcorner}=152.77, \dot{m}_{o}=160.27, T_{i\urcorner}=634$, dan $Q_{s h}=77103935$. 


\subsection{Simulasi Tanpa Gangguan}

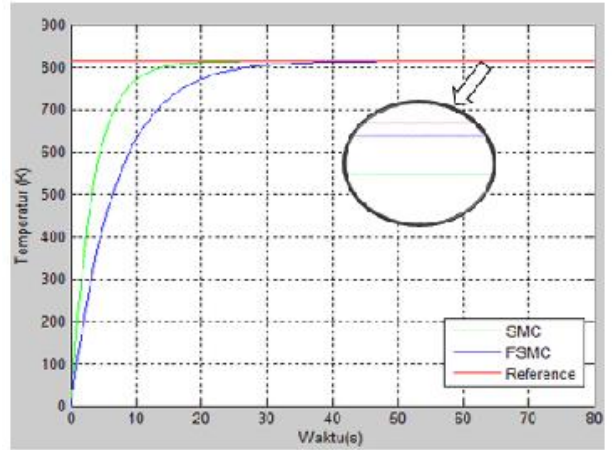

Gambar 8 Grafik Temperatur Uap tanpa Gangguan

Pada Gambar 8 tampak bahwa kondisi tanpa gangguan, sistem pengendali FSMC lebih lambat daripada pengendali SMC. Namun jika dilakukan pembesaran pada hasil simulasi diperoleh bahwa pengendali FSMC memiliki nilai error yang jauh lebih baik daripada SMC. Pengendali FSMC memiliki nilai error sebesar -0.0937 sedangkan pengendali SMC memiliki nilai error sebesar -0.5028. Pengendali FSMC dapat stabil disekitar $813.9 \mathrm{~K}$ sedangkan pengendali SMC stabil disekitar $813.5 \mathrm{~K}$.

\subsection{Simulasi dengan Gangguan Eksternal}

Telah dijelaskan sebelumnya bahwa masing-masing pengendali akan diberi gangguan yang berasal dari luar (eksternal) berupa sinyal impuls dan square. Sinyal impuls merupakan sinyal yang bernilai sangat besar dan muncul dalam waktu yang sangat singkat. Pada simulasi ini diberikan dua macam sinyal impuls. Yaitu yang bernilai kecil $(1 \mathrm{~kJ})$ dan bernilai besar $(5$ $\mathrm{kJ})$. Hasil yang diperoleh dari uji dengan sinyal ini adalah sebagai berikut.

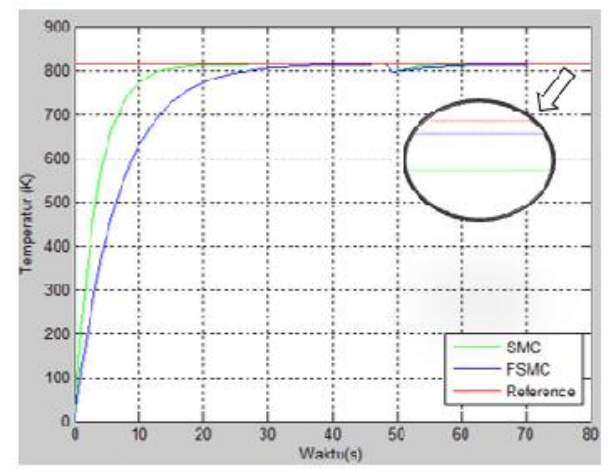

Gambar 9 Grafik Temperatur Uap dengan Sinyal Impuls 1 kJ 


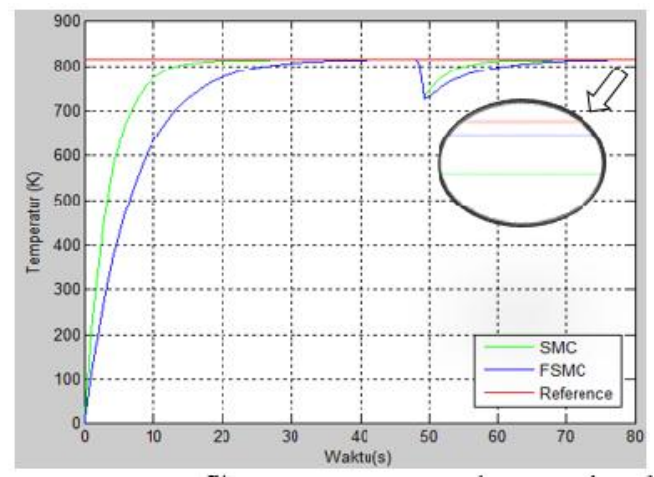

Gambar 10 Grafik Temperatur Uap dengan Sinyal Impuls 5 kJ

Dari Gambar 9 dan Gambar 10 nampak bahwa pada sistem dengan gangguan impuls kecil dan besar, pengendali SMC dan FSMC sama-sama memiliki respon yang cepat. Namun jika dilakukan pembesaran pada hasil simulasi diperoleh bahwa Pada Gambar 9 pengendali FSMC memiliki nilai error sebesar -0.114, pengendali SMC sebesar -0.5047. Sedangkan pada Gambar 10 pengendali FSMC memiliki nilai error sebesar -0.1136, pengendali SMC -0.5124. Pengendali FSMC dapat stabil disekitar $813.9 \mathrm{~K}$ sedangkan pengendali SMC stabil disekitar $813.5 \mathrm{~K}$.

Pada sinyal square, yaitu sinyal yang bernilai tetap untuk selang waktu tertentu. Pada simulasi ini diberikan dua macam sinyal square. Yaitu yang bernilai kecil $(1 \mathrm{~kJ})$ dan bernilai besar $(5 \mathrm{~kJ})$. Hasil yang diperoleh dari uji dengan sinyal ini adalah sebagai berikut.

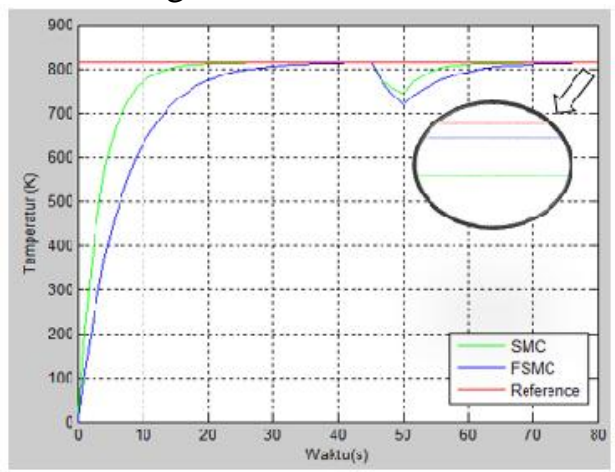

Gambar 11 Grafik Temperatur Uap dengan Sinyal Square 1 kJ

Pada Gambar 11 dan Gambar 12 terlihat bahwa pada sistem dengan gangguan square kecil maupun besar, pengendali FSMC masih memiliki respon yang lebih lambat daripada pengendali SMC. Namun jika dilakukan pembesaran pada hasil simulasi diperoleh bahwa pada Gambar 11, pengendali FSMC memiliki nilai error sebesar -0.118 sedangkan pengendali SMC memiliki nilai error sebesar -0.5126. Sedangkan pada Gambar 12, pengendali FSMC memiliki nilai error yang jauh lebih baik daripada SMC. Pengendali FSMC memiliki nilai error sebesar -0.1244 sedangkan pengendali SMC memiliki nilai error sebesar -0.5029. Pengendali FSMC dapat stabil disekitar 813.9 K sedangkan pengendali SMC stabil disekitar 813.5 K. 


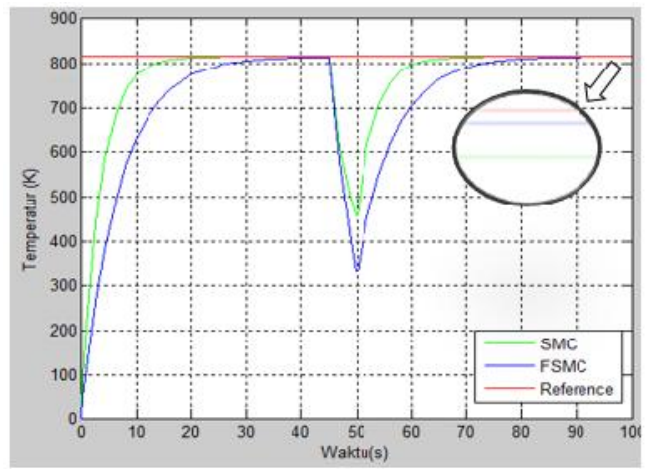

Gambar 12 Grafik Temperatur Uap dengan Sinyal Square 5 kJ

\subsection{Simulasi dengan Gangguan Internal}

Simulasi ini dilakukan dengan mengubah nilai parameter pada sistem superheater untuk menguji sensifitas sistem terhadap ketidakpastian dari dalam sistem. Parameter yang akan diubah adalah temperatur uap yang masuk, laju aliran massa yang masuk, laju aliran massa yang keluar dan kalor pembakaran pada superheater. Pengujian sistem pengendali terhadap gangguan internal ini dilakukan dengan memperbesar atau memperkecil nilai parameter sesuai batasan yang diberikan.

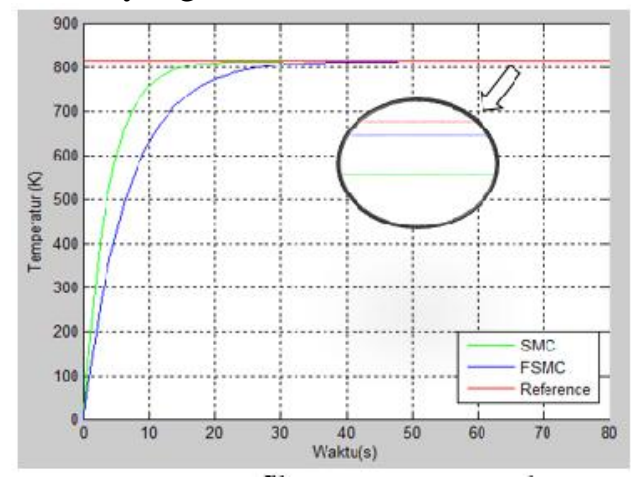

Gambar 13 Grafik Temperatur Uap dengan Parameter Diperkecil

Pada Gambar 13 terlihat bahwa pada sistem dengan parameter yang lebih kecil dari parameter awal, pengendali FSMC masih memiliki respon yang lebih lambat daripada pengendali SMC. Namun jika dilakukan pembesaran pada hasil simulasi diperoleh bahwa pengendali FSMC memiliki nilai error yang jauh lebih baik daripada SMC. Pengendali FSMC memiliki nilai error sebesar -0.1499 sedangkan pengendali SMC memiliki nilai error sebesar 0.5587. Pengendali FSMC dapat stabil disekitar $813.9 \mathrm{~K}$ sedangkan pengendali SMC stabil disekitar $813.5 \mathrm{~K}$. 


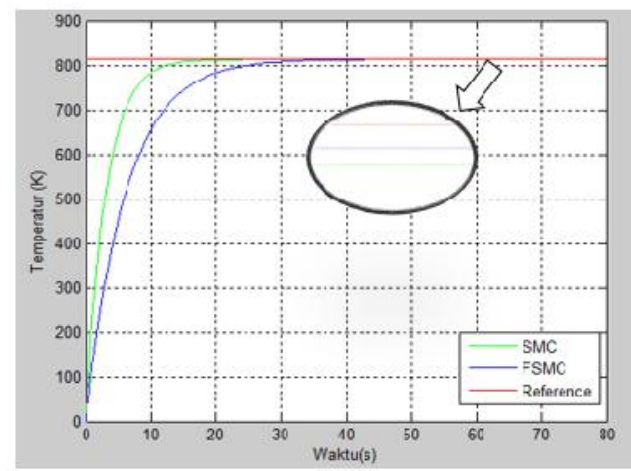

Gambar 14 Grafik Temperatur Uap dengan Parameter Diperbesar

Pada Gambar 14 terlihat bahwa pada sistem dengan parameter yang lebih besar dari parameter awal, pengendali FSMC masih memiliki respon yang lebih lambat daripada pengendali SMC. Namun jika dilakukan pembesaran pada hasil simulasi diperoleh bahwa pengendali FSMC memiliki nilai error yang lebih baik daripada SMC. Pengendali FSMC memiliki nilai error sebesar -0.0802 sedangkan pengendali SMC memiliki nilai error sebesar 0.1102. Pengendali FSMC dapat stabil disekitar 813.9 K sedangkan pengendali SMC stabil disekitar $813.8 \mathrm{~K}$.

\section{Kesimpulan dan Saran}

Berdasarkan hasil analisis dari hasil simulasi yang telah dilakukan yaitu diperoleh kesimpulan bahwa:

1. Rancangan pengendali FSMC pada sistem kendali temperatur uap superheater terdiri dari fungsi keanggotaan fuzzy, aturan fuzzy, dan susunan diagram blok dari sistem superheater. Rancangan pengendali FSMC dimulai dengan pembentukan fungsi switching $\mathrm{S}$, yaitu:

$$
\begin{aligned}
& S=\dot{\tilde{T}}+\lambda \tilde{T} \\
& \text { Dengan } \\
& \tilde{T}=T-T_{d} \\
& \dot{T}=\dot{T}-\dot{T}_{d}
\end{aligned}
$$

Permukaan slidingnya adalah :

$\dot{\tilde{T}}+\lambda \tilde{T}=0$

Setelah merancang bagian SMC, selanjutnya merancang bagian FLC, yaitu merancang fungsi keanggotaan dari $s_{p}$ dan $d$.

$$
\begin{gathered}
S_{p}=\frac{|\dot{\tilde{T}}+\lambda \tilde{T}|}{\sqrt{1^{2}+\lambda^{2}}} \\
d=\sqrt{\tilde{T}^{2}-s_{p}^{2}}
\end{gathered}
$$

2. Performansi sistem pengendalian temperatur uap superheater dengan metode FSMC menghasilkan temperatur uap dapat stabil disekitar 813.9 $\mathrm{K}$ baik tanpa gangguan maupun dengan gangguan eksternal dan internal. Angka ini sesuai dengan set point yang diharapkan yaitu $814 \mathrm{~K}$. 
Sedangkan dengan pengendali SMC temperatur uap dapat stabil di sekitar $813.5 \mathrm{~K}$. Jadi dapat dikatakan sistem pengendali FSMC mampu menghasilkan temperatur uap yang lebih akurat (error yang lebih kecil) dibandingkan dengan pengendali SMC. Selain itu, tingkat kerumitan dalam perancangan pengendali FSMC lebih sederhana dibandingkan dengan SMC.

Namun terdapat kekurangan yang dimiliki pengendali FSMC, yaitu membutuhkan waktu yang lebih lama daripada pengendali SMC dan juga membutuhkan penelaan gain agar logika fuzzy dapat bekerja dengan baik.

Dengan melihat hasil yang diperoleh pada penelitian ini, hal yang penulis sarankan untuk pengembangan selanjutnya yaitu, pengujian sistem pengendali FSMC pada superheater mendapatkan hasil yang cukup baik , namun sebaiknya perlu dikaji lebih lanjut apabila dibandingkan dengan model fuzzy yang lain seperti model fuzzy Takagi Sugeno atau dengan menggunakan metode yang lain seperti Type-2 Fuzzy Sliding Mode Control (T2FSMC).

\section{Pustaka}

[1] Herlambang, T (2010). "Desain Pengendalian Ketinggian Air dan Temperatur Uap pada Sistem Steam Drum Boiler dengan Metode Sliding Mode Control (SMC)”. Surabaya. Institut Teknologi Sepuluh Nopember.

[2] Stephanopoulos, George (1973). "Chemical Process Control". New Jersey : Prentice Hall.

[3] Mardlijah dkk. 2010."Design and Performance Analysis of Speed Controller in Induction Motor with Sliding Mode Control". ICRG ,Yogyakarta. Universitas Gadjah Mada.

[4] Ogata, Katshuiko. 2010. Modern Control Engineering. Prentice Hall Inc

[5] Tien, N.T. (2002). "Sliding Control." Applied Nonlinear Control. <URL: https://www2.hcmut.edu.vn/ nttien/Lectures/Applied\%20nonlinear\%20 control/C.7\%20Sliding\%20Control.pdf >.

[6] Ross, Timothy J. 2010. Fuzzy Logic with Engineering Application. USA: University of New Mexico.

[7] Palm, R., Driankov, D., dan Hellendoorn, H. (1997). "Model Based Fuzzy Control : Fuzzy Gain Schedulers and Sliding Mode Fuzzy Controllers". Berlin: Springer-Verlag

[8] Septiani, Mardiana (2015). "Metode Sliding Mode Control (SMC) pada Sistem Temperatur Uap Superheater di PLTU 3-4 PT. PJB UP Gresik". Laporan Kerja Praktek Jurusan Matematika. Surabaya. Institut Teknologi Sepuluh Nopember.

[9] Mardlijah dkk. 2007. "Disain Kontrol Posisi pada Panel Surya dengan Metode Fuzzy Sliding Mode Control (FSMC)”. Jurnal Limit Matematika ITS. 2007. Vol 4 No. 2. 